\title{
STUDY OF PERI-OPERATIVE COMPLICATIONS IN ASYMPTOMATIC SMOKERS POSTED FOR DAY CARE SURGERY
}

\author{
Bhabani Sankar Pati1 , Arun Rath2, Shakti Bedanta Mishra ${ }^{3}$
}

${ }_{1}^{1}$ Assistant Professor, Department of Anaesthesiology, IMS and SUM Hospital, Bhubaneswar, Odisha, India.

${ }^{2}$ Assistant Professor, Department of Anaesthesiology, IMS and SUM Hospital, Bhubaneswar, Odisha, India.

${ }^{3}$ Associate Professor, Department of Critical Care Medicine, IMS and SUM Hospital, Bhubaneswar, Odisha, India.

\section{ABSTRACT}

\section{BACKGROUND}

Cigarette smoking is a preventable cause of peri-operative respiratory complications, wound infection, myocardial infarction, stroke, and mortality. Smoking is associated with increased peri-operative complications. The primary objective of the study is to compare the nature, incidence of intra-operative \& post-operative complication in asymptomatic smokers subjected to day care surgery under general anaesthesia to that of non-smokers in our hospital.

\section{MATERIALS AND METHODS}

We conducted a prospective comparative study from July 2014 to October 2016 . The inclusion criteria were age between 16 to 60 years and male smokers who were asymptomatic for any respiratory problems due to smoking. Patient had to be having 5-pack years of smoking to be included in trial. Study parameters were observed during peri-operative period which was defined as: from the time of induction to shifting the patient out of post-anaesthesia care unit. Recovery time was defined as time of anaesthesia recovery to discharge from recovery room.

\section{RESULTS}

200 patients were recruited in the study, 100 in each group. Mean age was 43.3 years in smokers while 39.6 years in non-smokers. ASA class was similar in the two groups. Desaturation and coughing was observed at a statistically higher frequency in smokers in comparison to non-smokers. The exposure to smoking was dichotomised to more than 15-pack years of exposure and less for prediction of the complications mentioned above. Patient with more than 15-pack years' exposure had 1.67 times relative risk for desaturation, 1.56 times higher risk for bronchospasm. The time to recovery post anaesthesia till the discharge from the hospital was $171.4 \pm 37.1$ minutes in smokers and $153.7 \pm 32.3$ minutes in non-smokers. $(\mathrm{p}<0.01)$.

\section{CONCLUSION}

Smokers have a higher risk of peri-operative complications and need more time for recovery from anaesthesia in day care. Smokers with more than 15-pack years of exposure have higher risk of complications.

\section{KEYWORDS}

Smoking, Ambulatory Surgical Procedure, Anaesthesia Recovery Period.

HOW TO CITE THIS ARTICLE: Pati BS, Rath A, Mishra SB. Study of peri-operative complications in asymptomatic smokers posted for day care surgery. J. Evolution Med. Dent. Sci. 2017;6(32):2581-2584, DOI: 10.14260/Jemds/2017/558

\section{BACKGROUND}

Cigarette smoking is an avertable cause of peri-operative respiratory complications, wound infection, myocardial infarction, stroke, and mortality. ${ }^{1}$ Complications in smokers have been extensively studied. The relative risk of complications after surgery for smokers compared to nonsmokers is 4.3 fold higher. ${ }^{1}$ The adverse effects compromise the intended procedural outcomes and cost of care.2,3 Smoking has been shown to impair immunity as well as increase risk of cardiac complications. ${ }^{4-6}$ It has been found that the frequency and severity of different specific respiratory events are higher in smokers compared with nonsmokers. $^{7}$

Financial or Other, Competing Interest: None.

Submission 13-03-2017, Peer Review 08-04-2017,

Acceptance 15-04-2017, Published 20-04-2017.

Corresponding Author:

Dr. Shakti Bedanta Mishra,

IMS and SUM Hospital,

Bhubaneswar-751003,

Odisha, India.

E-mail: shaktimishra84@gmail.com

DOI: $10.14260 /$ jemds $/ 2017 / 558$

\section{(c) $($ ) $\Theta$}

Marginally higher inpatient costs were noted in smokers compared to non-smokers because of peri-operative respiratory complications. ${ }^{8}$

The primary objective of the study is to compare the nature and incidence of intra-operative \& post-operative complication in asymptomatic smokers subjected to day care surgery under general anaesthesia to that of non-smokers in our hospital.

\section{MATERIALS AND METHODS}

The present study was conducted in a tertiary care university hospital in India from July 2014 to October 2016 after obtaining due approval from the institutional ethical committee. The detail procedure was explained to each patient, informed written consent was obtained from them and the study was preceded.

This was a prospective comparative study. Data was collected from patients undergoing day care surgery under general anaesthesia. The Inclusion criteria were age between 16 to 60 years and male smokers who were asymptomatic for any respiratory problems due to smoking. Patient had to be having 5-pack years of smoking to be included in trial. Exclusion criteria were ASA III and above, unconscious 
patient, acute emergency surgery where preoperative evaluation not possible, age less than 16 years and patient with hypothermia or shivering who can give false reading on pulse oximetry. One hundred patients who satisfy the inclusion criteria were selected for smokers group of the study. One hundred non-smoker adult patients who belong to ASA I and II physical status coming for elective surgery are selected in control group.

Informed consent for anaesthesia, surgery and inclusion under the present study was taken after approval from institutional ethical committee. All the patients were allowed to take light and non-residual diet in the night of previous day of operation. All the patients were advised to remain nil orally after 12 a.m. midnight. All patients were pre-medicated with tablet Alprazolam $0.25 \mathrm{mg}$ on night before surgery and tablet Ranitidine $150 \mathrm{mg}$ on the night before and on the morning of day of surgery. On the day of surgery, patients were shifted to operation theatre 30 minutes before the schedule time. All the patients were pre-medicated with Injection Glycopyrrolate $0.04 \mathrm{mg} / \mathrm{kg}$ IV; Injection Fentanyl 1 microgram/kg slow IV; Injection Midazolam $0.05 \mathrm{mg} / \mathrm{kg}$ IV and Injection Ondansetron $4 \mathrm{mg}$ IV 15 minutes before induction of anaesthesia.

All patients were pre-oxygenated with $100 \%$ oxygen for 5 minutes. Induction was done with injection propofol 2.5 $\mathrm{mg} / \mathrm{kg}$ IV and to facilitate intubation by oral cuffed endotracheal tube muscle relaxation aided by injection vecuronium bromide $0.1 \mathrm{mg} / \mathrm{kg}$ IV. A direct laryngoscopy was started and tracheal intubation was completed within 15 seconds. Only first attempt was considered for evaluation of increase in heart rate during intubation. Bilateral airway entry was checked by auscultation. Anaesthesia was maintained by nitrous sevoflurane with controlled mechanical ventilation in closed circuit technique. Study parameters were observed during peri-operative period which was defined as from the time of induction to shifting the patient out of post-anaesthesia care unit. Recovery time was defined as time of anaesthesia recovery to discharge from recovery room.

\section{Assessments}

1) Arterial Oxygen Desaturation: This condition is recorded if pulse oximeter shows $\mathrm{SpO}_{2}$ value less than $92 \%$ for more than 1 minute, either during induction or maintenance or recovery from anaesthesia. 2) Laryngospasm: Incidence of audible stridor or airway obstruction, not relieved by airway manipulation by an expert anaesthetist. 3) Increase in heart rate during intubation which was dichotomised into two grades less than 20/min. and more than 20/min. 4) Bronchospasm: Audible wheezing or unexplained increase in airway pressure. 5) Increased oral secretions Grade 1 - Wet (Dry with one suction), Grade 2 - Moderate (2 - 3 suction), Grade 3 - Copious (More than 3 times) and Grade 4 - Thick secretions. 6) Severe coughing: More than 2 paroxysms or coughing for more than 5 seconds.

\section{Statistics}

Data are expressed as mean $\pm \mathrm{SD}$, percentages (\%), and numbers (n). Discrete variables were analysed using the chisquare $(\chi 2)$ test with a $p<0.05$ considered statistically significant. The exposure to smoking was dichotomised to more than 15-pack years and less than 15-pack years for prediction of the complications. The complications were individually analysed and also as a composite outcome. The statistical analysis was performed using a standard SPSS version 20 software package.

\section{RESULTS}

The study was conducted in a tertiary care university hospital in India from July 2014 to October 2016. 200 patients were recruited in the study, 100 in each group. Mean age was 43.3 years in smokers while 39.6 years in non-smokers. ASA class was similar in the two groups. Upper abdominal and lower abdominal surgeries were also similar between the groups. The smokers had a mean 18.3-pack years between them. Both groups were comparable in terms of demographics and surgical procedure being undertaken.

The complications were noted in both groups. Desaturation and coughing was observed at statistically higher frequency in smokers in comparison to non-smokers. Laryngospasm and Bronchospasm were also higher in smokers though it was not statistically significant. The increase in heart rate during intubation was statistically more in the patients who were smokers. Smokers also had higher frequency of having copious and thick secretions in comparison to non-smokers.

The exposure to smoking was dichotomised to more than 15-pack years of exposure and less for prediction of the complications mentioned above. Patient with more than 15pack years exposure had 1.67 times relative risk for desaturation, 1.56 times higher risk for bronchospasm, 2.54 times risk for tachycardia following intubation and 2.14 times risk for developing thick and copious secretions post extubation was recorded in patients with more than 15-pack years of exposure.

The surgery time and anaesthesia time was comparable in the two groups. In smokers, the surgery duration was $52.9 \pm$ 18.5 minutes and in non-smokers $52.3 \pm 17.8$ minutes $(\mathrm{p}=$ 0.81 ). In smokers, the anaesthesia duration was $66.4 \pm 18.8$ minutes and in non-smokers $66.3 \pm 18.2$ minutes $(p=0.94)$. The time to recovery post anaesthesia till the discharge from the hospital was $171.4 \pm 37.1$ minutes in smokers and $153.7 \pm$ 32.3 minutes in non-smokers. $(\mathrm{p}<0.01)$.

\begin{tabular}{|c|c|c|c|c|}
\hline & $\begin{array}{c}\text { All } \\
\text { Patients } \\
(n=200)\end{array}$ & $\begin{array}{l}\text { Smokers } \\
(n=100)\end{array}$ & $\begin{array}{c}\text { Non- } \\
\text { Smokers } \\
(n=100)\end{array}$ & $\begin{array}{c}P \\
\text { value }\end{array}$ \\
\hline Age & $41.1 \pm 11.6$ & $43.3 \pm 11.7$ & $39.6 \pm 11.2$ & 0.23 \\
\hline \multicolumn{5}{|l|}{ ASA status } \\
\hline I & 128 & 58 & 70 & \multirow{2}{*}{0.10} \\
\hline II & 72 & 42 & 30 & \\
\hline \multicolumn{5}{|l|}{ Procedure } \\
\hline $\begin{array}{c}\text { Upper } \\
\text { Abdomen }\end{array}$ & 112 & 62 & 50 & \multirow{2}{*}{0.65} \\
\hline $\begin{array}{c}\text { Lower } \\
\text { Abdomen }\end{array}$ & 88 & 45 & 43 & \\
\hline Pack Years & & $18.3 \pm 10.4$ & 0 & $>0.01$ \\
\hline
\end{tabular}




\begin{tabular}{|c|c|c|c|}
\hline & $\begin{array}{c}\text { Smoker } \\
(\mathbf{n = 1 0 0 )}\end{array}$ & $\begin{array}{c}\text { Non-Smoker } \\
(\mathbf{n}=\mathbf{1 0 0})\end{array}$ & p-value \\
\hline Desaturation & 26 & 8 & $<0.01$ \\
\hline Laryngospasm & 10 & 2 & 0.01 \\
\hline Bronchospasm & 10 & 6 & 0.29 \\
\hline Coughing & 34 & 10 & $<0.01$ \\
\hline $\begin{array}{c}\text { Increased Heart } \\
\text { Rate }\end{array}$ & 94 & 52 & $<0.01$ \\
\hline Increased & \multicolumn{3}{|}{} \\
Secretions & & 4 & \\
Grade 1 & 4 & 90 & $<0.01$ \\
Grade 2 & 38 & 6 & \\
Grade 3 & 56 & 0 & \\
Grade 4 & 2 & \multicolumn{3}{|c|}{} \\
\hline \multicolumn{2}{|c|}{ Table 2. Frequency of Peri-operative Complication } \\
\hline
\end{tabular}

\begin{tabular}{|c|c|c|c|}
\hline \multirow{2}{*}{ Parameters } & Relative & \multicolumn{2}{|c|}{ 95\% Confidence Interval } \\
\cline { 3 - 4 } & Risk & Lower Limit & Upper Limit \\
\hline Desaturation & 1.67 & 1.21 & 2.31 \\
\hline Laryngospasm & 1.56 & 1.08 & 2.26 \\
\hline Bronchospasm & 1.12 & 0.64 & 1.93 \\
\hline Coughing & 0.67 & 0.43 & 1.06 \\
\hline $\begin{array}{c}\text { Increased Heart } \\
\text { Rate }\end{array}$ & 2.54 & 1.96 & 3.29 \\
\hline $\begin{array}{c}\text { Increased } \\
\text { Secretion }\end{array}$ & 2.14 & 1.38 & 3.33 \\
\hline $\begin{array}{c}\text { Table 3. Relative Risk of Developing Complications in } \\
\text { Patients with more than 15-Pack years }\end{array}$ \\
\hline
\end{tabular}

\section{DISCUSSION}

World Health Organization states that $12 \%$ of smokers in the world are in India. Smoking has various adverse effects on health which is well established.9,10 Jha et al ${ }^{11}$ have estimated that around 1 million deaths a year in India are attributable to smoking. A Turan et al ${ }^{1}$ evaluated 103,795 smokers and found that smoking was associated with a $40 \%$ increased odds of 30-day mortality and a 30-100\% increase odds of major morbidity, including surgical site infection, pneumonia, unplanned intubation, and septic shock.

The aim of our study was to find out how smoking affected and caused peri-operative respiratory complications in patients undergoing day care surgery. Moore et al ${ }^{12}$ observed that 1 to 2 weeks may be enough to reduce sputum volume. A systematic review of 25 studies on the optimal timing of smoking cessation by Wong et al ${ }^{13}$ concluded that at least 4 weeks of abstinence from smoking reduced respiratory complications, and abstinence of at least 3 to 4 weeks reduced wound healing complications. There are limited trials which have looked in to the impact of smoking on patient who are posted for day care surgeries.

In our study, we found that desaturation, coughing were more in smokers, about 1.67 times more than non-smokers, similarly laryngospasm and bronchospasm, tachycardia were also more in smokers than in non-smokers. Laxton $\mathrm{CH}$ et al,14 Tait et al,15 Myles et al ${ }^{16}$ also observed similar incidence of peri-operative respiratory events (PRE) associated with smoking and when the cessation of smoking is helpful in decreasing these PREs.

In our study, the recovery to discharge time from the hospital was $171.4 \pm 37.1$ minutes in smokers and $153.7 \pm$
32.3 minutes in non-smokers. There was significantly prolonged time to discharge smokers than non-smokers. This in day care surgery adds to the burden of keeping patients under observation for a longer duration in the recovery room and prolongs the discharge process. ${ }^{17-19}$

We also dichotomised the exposure to cigarette smoking to more than 15-pack years' exposure and less than 15-pack years' exposure. Patients who had higher exposure had 1.67 times relative risk for desaturation, 1.56 times higher risk for bronchospasm, 2.54 times risk for tachycardia following intubation and 2.14 times risk for developing thick and copious secretions post extubation than that of less than 15pack years. This could help in predicting which patient may have more complications as in prior trials. ${ }^{20}$ The limitation of our study is that the study population is very less. Since the data is limited in this field we felt the need to do this pilot project to see if there is any impact of smoking on recovery of patients in day care procedures.

In summary, our observation indicates that smoking is associated with higher peri-operative risk for day care procedures, also increased the anaesthesia recovery time in general by demonstrating that the number of adverse outcomes are higher in smokers. Future observations on larger population can give us more concrete evidence on smoking association with prolonged recovery time and perioperative respiratory complications.

\section{CONCLUSION}

Smokers have a higher risk of perioperative complications and need more time for recovery from anaesthesia in day care. Smokers with more than 15-pack years of exposure have a higher risk of complications.

\section{REFERENCES}

[1] Turan A, Mascha EJ, Roberman D, et al. Smoking and peri-operative outcomes. Anaesthesiology 2011;114(4):837-46.

[2] Lee A, Chui PT, Chiu CH, et al. Risk of peri-operative respiratory complications and postoperative morbidity in a cohort of adults exposed to passive smoking. Annals of surgery 2015;261(2):297-303.

[3] Graybill WS, Frumovitz M, Nick AM, et al. Impact of smoking on peri-operative pulmonary and upper respiratory complications after laparoscopic gynecologic surgery. Gynecologic oncology 2012;125(3):556-60.

[4] Rodrigo C. The effects of cigarette smoking on anesthesia. Anesthesia progress 2000;47(4):143-50.

[5] Kotani N, Hashimoto H, Sessler DI, et al. Smoking decreases alveolar macrophage function during anesthesia and surgery. Anesthesiology 2000;92(5):1268-77.

[6] Woehlck HJ, Connolly LA, Cinquegrani MP, et al. Acute smoking increases ST depression in humans during general anesthesia. Anesthesia and analgesia 1999;89(4):856-60.

[7] Saxena A, Shan L, Reid C, et al. Impact of smoking status on early and late outcomes after isolated coronary artery bypass graft surgery. Journal of cardiology 2013;61(5):336-41. 
[8] Schmid M, Sood A, Campbell L, et al. Impact of smoking on peri-operative outcomes after major surgery. American journal of surgery 2015;210(2):221-9 e6.

[9] Pearce AC, Jones RM. Smoking and anesthesia: preoperative abstinence and peri-operative morbidity. Anesthesiology 1984;61(5):576-84.

[10] Moller AM, Villebro N, Pedersen T, et al. Effect of preoperative smoking intervention on postoperative complications: a randomised clinical trial. Lancet 2002;359(9301):114-7.

[11] Jha P, Jacob B, Gajalakshmi V, et al. A nationally representative case-control study of smoking and death in India. The New England journal of medicine 2008;358:1137-47.

[12] Moore S, Mills BB, Moore RD, et al. Perisurgical smoking cessation and reduction of postoperative complications. American journal of obstetrics and gynecology 2005;192(5):1718-21.

[13] Wong J, Lam DP, Abrishami A, et al. Short-term preoperative smoking cessation and postoperative complications: a systematic review and meta-analysis. Canadian journal of anaesthesia 2012;59(3):268-79.

[14] Laxton CH, Milner Q, Murphy PJ. Haemodynamic changes after tracheal intubation in cigarette smokers compared with non-smokers. British journal of anaesthesia 1999;82(3):442-3.
[15] Tait AR, Kyff JV, Crider B, et al. Changes in arterial oxygen saturation in cigarette smokers following general anaesthesia. Canadian journal of anaesthesia 1990;37(4 Pt 1):423-8.

[16] Myles PS, Iacono GA, Hunt JO, et al. Risk of respiratory complications and wound infection in patients undergoing ambulatory surgery: smokers versus nonsmokers. Anesthesiology 2002;97(4):842-7.

[17] Sarin P, Philip BK, Mitani A, et al. Specialized ambulatory anesthesia teams contribute to decreased ambulatory surgery recovery room length of stay. The Ochsner journal 2012;12(2):94-100.

[18] Vinoles J, Ibanez MV, Ayala G. Predicting recovery at home after ambulatory surgery. BMC health services research 2011;11:269.

[19] Tomal CRG, Silva AG, Yamashita AM, et al. Assessment of induction, recovery, agitation upon awakening, and consumption with the use of two brands of sevoflurane for ambulatory anesthesia. Revista brasileira de anestesiologia 2012;62(2):154-72.

[20] Stoner MC, Abbott WM, Wong DR, et al. Defining the high-risk patient for carotid endarterectomy: an analysis of the prospective national surgical quality improvement program database. Journal of vascular surgery 2006;43(2):285-95. 